\title{
Improving health literacy through group antenatal care: a prospective cohort study
}

\author{
Jody R. Lori ${ }^{1 *}$, Henrietta Ofosu-Darkwah², Carol J. Boyd ${ }^{1}$, Tanima Banerjee ${ }^{3}$ and Richard M. K. Adanu ${ }^{4}$
}

\begin{abstract}
Background: To examine whether exposure to group antenatal care increased women's health literacy by improving their ability to interpret and utilize health messages compared to women who received standard, individual antenatal care in Ghana.

Methods: We used a prospective cohort design. The setting was a busy urban district hospital in Kumasi, the second most populous city in Ghana. Pregnant women $(N=240)$ presenting for their first antenatal visit between 11 and 14 weeks gestation were offered participation in the study. A 27\% drop-out rate was experienced due to miscarriage, transfer or failure to return for follow-up visits, leaving 184 women in the final sample. Data were collected using an individual structured survey and medical record review. Summary statistics as well as two sample t-tests or chi-square were performed to evaluate the group effect.
\end{abstract}

Results: Significant group differences were found. Women participating in group care demonstrated improved health literacy by exhibiting a greater understanding of how to operationalize health education messages. There was a significant difference between women enrolled in group antenatal care verses individual antenatal care for preventing problems before delivery, understanding when to access care, birth preparedness and complication readiness, intent to use a modern method of family planning postpartum, greater understanding of the components of breastfeeding and lactational amenorrhea for birth spacing, and intent for postpartum follow-up.

Conclusion: Group antenatal care as compared to individual care offers an opportunity to increase quality of care and improve maternal and newborn outcomes. Group antenatal care holds the potential to increase healthy behaviors, promote respectful maternity care, and generate demand for services. Group ANC improves women's health literacy on how to prevent and recognize problems, prepare for delivery, and care for their newborn.

\section{Background}

While significant progress was made towards meeting Millennium Development Goals 4 and 5, the quest remains to end preventable maternal and perinatal deaths. Over the past two decades, there has been a focus on increasing access to the recommended four antenatal care (ANC) visits and Basic Emergency Obstetric Care (BEmONC). Globally, this focus has been successful with more than $71 \%$ of births assisted by a skilled birth attendant in 2014, compared to 59\% in 1990 and concomitantly, a decline in under-five mortality rates from 90 to 43 deaths per 1000 live births [1].

\footnotetext{
*Correspondence: jrlori@umich.edu

'Department of Health Behavior and Biological Sciences, University of Michigan, School of Nursing, 400 N. Ingalls Bldg, Ann Arbor, MI 48109, USA Full list of author information is available at the end of the article
}

However, it is clear that more needs to be done. It is estimated that every year over 300,000 women die from complications related to pregnancy and childbirth, 2.6 million stillbirths occur, and 2.8 million newborns continue to die during their first 28 days of life [2, 3]. Antenatal care has been identified as a key strategy to maintaining a health pregnancy and promoting thriving families and communities [4]. If health literacy was improved and the use of skilled birth attendants increased further, women and newborn lives could be saved - and morbidity drastically reduced $[1,2]$.

Initially considered only as a patient's ability to read and understand written information, health literacy is now more broadly defined as a person's ability to acquire or access information, understand, and finally use the information in ways that promote and maintain good health $[5,6]$. Despite a burgeoning emphasis on health 
literacy in high-resource countries [7], there are a dearth of studies to improve health literacy in low and middle income countries, particularly interventions focused on maternal health literacy [8]. To reduce inequalities in maternal and newborn outcomes, an approach of contextually appropriate health messaging must be constructed [9].

\section{Antenatal care}

Focused Antenatal Care, introduced in early 2000 emphasizes quality over quantity and consists of a welldefined set of activities in a four-visit model with individuals receiving care from a consistent provider for continuity of care [10]. However, recent studies have found the reduced visit model associated with increased perinatal mortality and less satisfaction with care among pregnant women [11, 12]. Current recommendations support a shift toward coverage of ANC content rather than contact with an agreed upon set of key ANC services (i.e. full protection against tetanus toxoid, ironfolate supplementation for at least 90 days, counseling on danger signs, etc.) [13].

Alternatively, group care provides ANC content in small groups of women at similar gestational age and facilitated by a consistent provider. Women remain in the same group throughout their pregnancy, thereby enhancing information sharing and peer support among group members [14]. Widely accepted components of group care include sitting in a circle, interactive learning, planned activities, stability of group members and provider, and creating an environment where women learn from and support one another $[15,16]$.

Recent studies examining individual ANC in lowresource settings, have highlighted several problems with the way current care is most often delivered. Very little time is spent with pregnant women, important information is not reinforced, efficiency is poor, relationships between providers and clients are not fostered, and there is a lack of patient centeredness [17, 18]. Additionally, research has shown very low understanding by pregnant women of the actions required for birth preparedness and complication readiness [19-21]. For example, knowledge on the risks associated with vaginal bleeding, convulsions/fits, severe headaches with blurred vision, fever and weakness, severe abdominal pain, and fast or difficult breathing is often misunderstood by pregnant women [22].

A group format for delivery of care has advantages over individual care that include improved efficiency, access, patient satisfaction, provider satisfaction, and health outcomes [15, 23]. Similar to other types of group care, group ANC visits have been found to be acceptable to pregnant women and have been associated with improved outcomes in preterm birth, breast feeding initiation, patient satisfaction, and family planning in the
United States using the Centering Pregnancy model [16, 24-27]. Globally, the feasibility of implementing group ANC has been examined in Iran, Tanzania, Malawi, and Ghana and found to be acceptable to both pregnant women and providers [14, 25, 28]. Group ANC holds the potential for not only increasing patient satisfaction, but also increasing a mother's knowledge and ability to utilize the health messages she receives during antenatal care.

The aim of this study was to examine whether exposure to group ANC increases Ghanaian women's health literacy by improving their ability to interpret and utilize health messages impacting health related behaviors and ultimately improving birth outcomes. The overall goal was to quantify the potential impact of group ANC in a low-resource setting.

\section{Methods}

\section{Description of the group ANC model}

The group ANC model used for this study was modified from a curriculum initially developed by the American College of Nurse-Midwives to mobilize communities in low-resource countries for early problem identification of pregnancy related problems and referral [29]. Using the WHO Standards for Maternal and Neonatal Care [30] the group ANC model was developed and tested for acceptability and feasibility for the first time in a clinical setting in Ghana [14].

A Facilitator's Guide provides step-by-step details on how to conduct each of the 7 group ANC visits. Seven modules were developed covering the essential elements of ANC [31-35] (Table 1). The Facilitator's Guide also includes chapters on preparing for and implementing group care, becoming a facilitator, enhancing adult learning, respectful maternity care, and monitoring for program quality, performance, and fidelity. The model uses a collaborative approach between providers and pregnant women with respect for all types of knowing.

Following the initial ANC visit, pregnant women are grouped into small groups with 12 women of similar gestational age. Prior to the start of each group, blood pressure, weight, and a urinalysis are measured on each

Table 1 Group Antenatal Care Modules

\begin{tabular}{ll}
\hline Module & Topic \\
\hline ANC Visit 1 & Introduction to Group ANC and Topics \\
ANC Visit 2 & Self- Care and Preventing Problems During Pregnancy \\
ANC Visit 3 & Danger Signs \\
ANC Visit 4 & Birth Preparedness and Complication Readiness \\
ANC Visit 5 & Preventing Problems After Your Baby is Born \\
ANC Visit 6 & Family Planning and Exclusive Breastfeeding \\
ANC Visit 7 & Preventing and Recognizing Newborn Problems \\
\hline
\end{tabular}


woman. She then receives an individual assessment with the provider to measure fundal height, listen to fetal heart tones, and answer any questions she prefers not to raise in the group. Pregnant women and providers then sit in circle facing one another for a 60-min facilitated discussion. The teaching component uses strategies such as story-telling, peer support, demonstration and teachback - capturing and sharing experiences among the pregnant women to enhance its effectiveness. Improving health literacy is incorporated as an integral part of clinical practice within the model. Evidence-based information is presented in a non-hierarchical, patient centered, participatory manner.

Because the model was developed for use in lowresource settings and with women who often have not had the opportunity to attend formal school, picture cards are used as visual images to enhance communication and learning in the group setting $[14,21]$. They provide a mechanism to envision new concepts and ideas. The picture cards provide a valuable group discussion and learning aid to stimulate thinking and reflection, dialogue, and learning among participants. Content is repeated multiple times in multiple ways to enhance retention including: 1) auditory by listening to stories and signs of problems; 2) visual through use of demonstration and picture cards; 3) kinesthetically by practicing actions and "handling" picture cards; and 4) reminder pictures for home use.

\section{Study setting}

Ghana is a low income country in sub-Saharan West Africa with a maternal mortality ratio of 319 per 100,000 [2], a perinatal mortality rate of 38 per 1000 live births, and an infant mortality rate of 41 deaths per 1000 live births [36]. While $87.3 \%$ of women in Ghana surveyed had attended the minimum standard of 4 ANC visits, $27 \%$ gave birth alone or with a non-skilled attendant [36]. Only $22.8 \%$ of newborns in Ghana received the recommended postnatal check-up within the first 2 days of life between 2012 and 2014 [36]. Since 2008, there has been only a marginal decline (3\%) in neonatal mortality within Ghana [36].

\section{Study design}

A prospective cohort design was used for this study. The comparison group received the standard individualized focused ANC by the same group of providers. The teaching component for women in individual care consisted of the midwife providing information in a lecture format to all women who presented for care that day on standard ANC educational content (i.e. danger signs, breastfeeding, birth preparedness and complication readiness, etc.) prior to their individual appointment with the midwife. The same educational content was presented as a facilitated discussion in the intervention group. Other than group vs. individual care, the two groups received identical antenatal treatment following the clinic guidelines [10]. Women enrolled in the study were encouraged to attend 7 ANC visits following the initial enrollment visit every 4 weeks until 36 weeks gestation and then every 2 weeks until 40 weeks gestation. Women were followed longitudinally from the time of entry into ANC through the postpartum period.

Institutional review board approval for the study was obtained from the University of Ghana Noguchi Memorial Institute for Medical Research; the Kwame Nkrumah University of Science and Technology Committee on Human Research, Publications and Ethics; and the University of Michigan's Institutional Review Board.

\section{Sample}

A facility-driven convenience sample of 240 Ghanaian women presenting for their first ANC visit between 11 and 14 weeks gestation, at a busy urban district hospital were recruited for the study. Any woman over the age of 18 years, who spoke English or Twi, was currently between 11 and 14 weeks gestation, and enrolling for ANC at the identified district hospital clinic was offered participation in the study. The research assistant met with each woman in a private area of the clinic to explain the study, answer questions, and obtain informed consent. A written informed consent was used. If women were unable to read, the research assistant read the document to them. All women provided written consent through a signature or mark entered onto the informed consent document. Every other woman presenting for her first visit, who agreed to participate in the study, was alternately enrolled into either group or individual care. Women meeting inclusion criteira were recruited consecutively until 10 groups consisting of 12 participants and 120 participants for individual care were reached. No individual refused participation.

Sample size was set by power calculations for a two group continuity corrected chi-square test with a 0.05 two-sided significance level and $80 \%$ power to detect a difference in knowledge acquisition between the two groups. The calculations were performed to detect a medium size effect of 0.5 as defined by Cohen [37]. Power analysis was conducted with nQuery Advisor 7.0 software [38]. From these calculations, a sample size of 73 was required per group. Anticipating the potential for a high attrition rate during the course of the study because of the known mobility patterns and potential loss to follow up in this peri-urban community, we employed an over sampling strategy.

\section{Measures}

Demographic data were collected on all pregnant women at the beginning of the study. The study utilized 
individual survey questions and chart review for data collection. Survey questions were adapted from the Home Based Life Saving Skills evaluation toolkit [29]. The survey was assessed for both face and content validity by US and Ghanaian researchers familiar with antenatal care research in Ghana in particular, and subSaharan Africa in general. Questions were refined to assure comprehension of the concepts in the Ghanaian context. The survey included 37 questions to capture the knowledge gained by pregnant women during their experiences with antenatal care; 4 short answer, 18 dichotomous (yes/no) questions, and 15 recall questions to assess self-care knowledge, birth preparedness, complication readiness, breastfeeding knowledge, and postpartum danger signs. Measurement tools are available, Additional files 1, 2, and 3.

\section{Study data collection}

The individual survey took approximately $20-30 \mathrm{~min}$ to complete. Women were informed they could refuse to answer any question or stop the survey at any time. Data were collected by the research assistant following birth using a face-to-face individual structured survey. Due to low literacy, the survey was administered verbally by the research assistant. Women were given an incentive of baby items worth approximately 8 US dollars upon completion of the survey. A medical record review was also conducted to obtain information on birth weight, number of ANC visits, mode of delivery, and maternal and perinatal morbidities and mortalities.

\section{Data analysis}

All data were first entered into an excel spreadsheet and transferred to SAS 9.4 (SAS Institute Inc., Cary, NC, USA) for analyses. Summary statistics based on mean, standard deviation, or frequency were carried out for the exploratory analysis. Two sample t-tests or chi-square tests were performed to evaluate the group effect for demographic, individual surveys, and chart view items depending on the type of variables (continuous or categorical). Significance was determined at $p<.05$.

\section{Results}

Two-hundred forty women were enrolled in the study. Fifty-seven women dropped from the study due to miscarriage, transfer to another facility, or failure to return after initial visit (cause unknown) for a retention rate of $72.6 \%$. One-hundred eighty-three women were followed from the time of enrollment through postpartum. One hundred women participated in group care and 83 women received individual focused antenatal care (Fig. 1).

The average age of women was 27.9 years $(\mathrm{SD}=5.7)$. There was a significant, although not clinical, difference in age between the groups with women enrolled in group care on average 2 years older than women enrolled in individual care ( 28.8 vs. 26.7 years). Additionally, more individuals assigned to group care identified their religious affiliation as Christians (67.3\%) verses Muslim (30.6\%). Results were stratified during analysis to examine for any significant differences based on demographic differences. There were no significant differences in parity, age, and religious affiliation between groups on all outcome measures. Overall, only $32.9 \%$ of all women in the study reported completing any high school or higher education. Although not statistically significant, approximately $35 \%$ of women enrolled in individual care reported they were unable to read or write vs. $25 \%$ of women enrolled in group care. See Table 2 for a full description of demographic and descriptive statistics.

\section{Improved self-care knowledge to prevent problems}

Following delivery, women were asked to recall what they learned during ANC to help them care for themselves during pregnancy. Women in group care recalled learning more self-care behaviors to help them remain
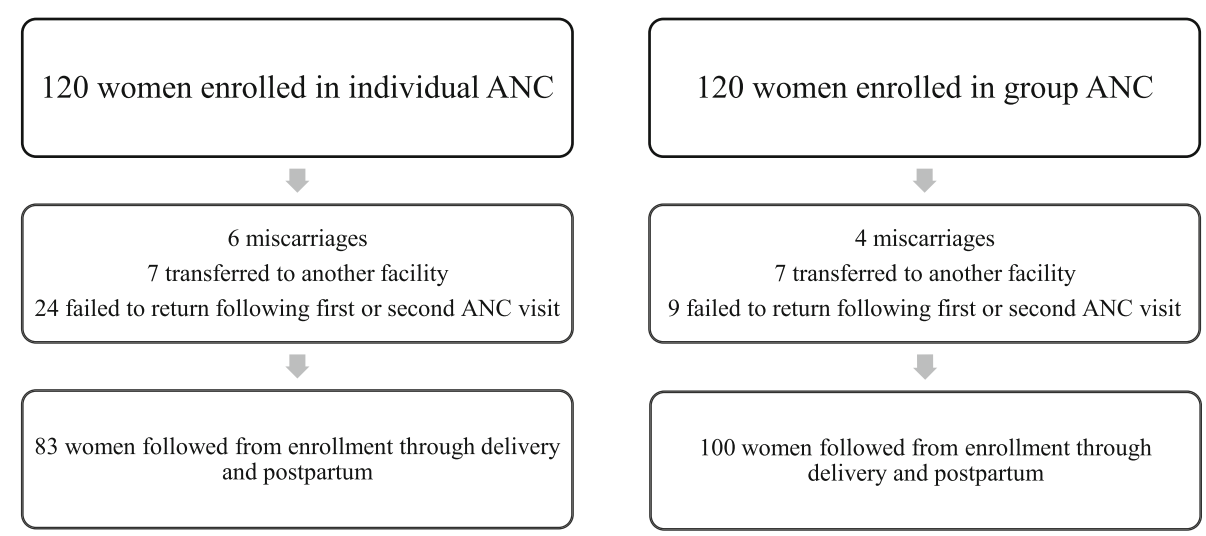

Fig. 1 Flow Diagram of Enrollment 
Table 2 Demographic Data

\begin{tabular}{llll}
\hline & Group $(N=100)$ & Individual $(N=83)$ & $p$ value \\
\hline Age at last birthday & & & \\
$\quad$ Mean (SD) & $28.8(5.8)$ & $26.7(5.4)$ & $\mathbf{0 . 0 2 *}$ \\
Religious following & & & \\
$\quad$ Missing & 2 & 2 & \\
None & $2(2.0 \%)$ & $0(0.0 \%)$ &
\end{tabular}

$\begin{array}{lll}\text { Christian } & 66(67.3 \%) & 43(53.1 \%) \\ \text { Muslim } & 30(30.6 \%) & 38(46.9 \%)\end{array}$

Marital status

$\begin{array}{llll}\text { Married } & 73(73.0 \%) & 57(68.7 \%) & 0.52 \\ \text { Single } & 27(27.0 \%) & 26(31.3 \%) & \\ \text { Ever attended school } & & & \\ \text { Missing } & 1 & 0 & 0.63 \\ \text { No } & 13(13.1 \%) & 13(15.7 \%) & \\ \text { Yes } & 86(86.9 \%) & 70(84.3 \%) & \end{array}$

Highest level of school attended

$\begin{array}{lll}\text { Missing } & 13 & 15 \\ \text { Primary } & 21(24.1 \%) & 13(19.1 \%) \\ \text { Jr. High school } & 36(41.4 \%) & 34(50.0 \%) \\ \text { Sr. High school } & 18(20.7 \%) & 11(16.2 \%) \\ \text { Tertiary } & 12(13.8 \%) & 10(14.7 \%) \\ \text { Able to read } & & \\ \text { Missing } & 1 & 0 \\ \text { No } & 25(25.3 \%) & 29(34.9 \%) \\ \text { Yes } & 74(74.7 \%) & 54(65.1 \%)\end{array}$

Able to write

$\begin{array}{lll}\text { Missing } & 0 & 1 \\ \text { No } & 24(24.0 \%) & 29(35.4 \%) \\ \text { Yes } & 76(76.0 \%) & 53(64.6 \%)\end{array}$

Number of pregnancies

$\begin{array}{ccc}\text { Mean (SD) } & 3.2(1.7) & 2.9(1.5) \\ \text { Range } & (1.0-7.0) & (1.0-7.0) \\ \text { Primigravida } & 17(17 \%) & 15(18 \%)\end{array}$

Number of living children

$\begin{array}{lll}\text { Mean (SD) } & 1.6(1.5) & 1.3(1.3) \\ \text { Range } & (0.0-5.0) & (0.0-5.0)\end{array}$

Travel time to district hospital

$\begin{array}{lll}\text { Mean (SD) } & 1.1(0.3) & 1.1(0.3) \\ \text { Range } & (1.0-3.0) & (1.0-2.0)\end{array}$

Type of transportation to hospital

Missing

7
Table 2 Demographic Data (Continued)

\begin{tabular}{llll}
\hline Car & $5(5.4 \%)$ & $2(2.6 \%)$ & \\
Walk & $14(15.1 \%)$ & $16(20.8 \%)$ & 0.46 \\
Taxi & $17(18.3 \%)$ & $18(23.4 \%)$ & \\
Tro-tro (mass transit) & $57(61.3 \%)$ & $41(53.2 \%)$ & \\
\hline${ }^{*} p \leq .05$ & &
\end{tabular}

healthy during their pregnancy such as, drinking plenty of fluids $(\mathrm{p}=<0.01)$ and getting additional rest $(p=0.01)$. Twice as many women enrolled in group care (38\%) reported they were instructed to watch for problems and report to the clinic when they identified a problem than women receiving individual care (18.3\%) $p=0.01$. Women in group care also reported they were more often instructed by their midwife on nutrition and to eat adequate foods. Overall, there was a significant difference in the overall number of self-care measures recalled among women attending group $\mathrm{ANC}(\mathrm{M}=6.0$, $\mathrm{SD}=0.87)$ vs. individual ANC $(\mathrm{M}=5.05, \mathrm{SD}=1.21)$, $(p=0.01)$ (Table 3).

\section{Birth preparedness and complication readiness}

Women enrolled in group ANC visits were more likely to have arrangements made in advance for emergency transport should a problem occur $(p=0.001)$ and to have saved money in preparation for birth $(\mathrm{p}=<0.001)$. They also reported more frequently discussing with their midwife where they would deliver $(p=0.001)$. Women participating in group ANC reported being more influenced by their midwife during ANC on their choice of where to deliver $(p=0.001)$ than women receiving individual care (Table 4). Overall, women attending group care were able to recall more danger signs $(M=3.49$, $\mathrm{SD}=0.88)$ compared to women in individual care $(\mathrm{M}=3.12, \mathrm{SD}=0.93),(p=0.01)$.

\section{Breastfeeding knowledge}

Women attending group ANC had significantly more knowledge on practices to promote exclusive breastfeeding than women receiving standard, individual care. More women enrolled in group care $(90 \%)$ vs. individual care $(66.3 \%)$ were aware to start breastfeeding as soon as possible after birth $(\mathrm{p}=<0.01)$ and a greater percentage (90\% vs. $75.9 \%)$ reported they should breastfeed exclusively until the baby is at least 6 months of age $(\mathrm{p}=<0.01)($ Table 5$)$.

\section{Newborn and postpartum self-care knowledge}

More women receiving group care reported discussing newborn problems during their ANC visits with the midwife $(\mathrm{p}=<0.01)$. They also were more likely to be aware that excessive bleeding postpartum is a problem 
Table 3 Self-Care Knowledge to Prevent Problems

\begin{tabular}{llll}
\hline Topic & Group $(n=100)$ & Individual $(n=83)$ & $p$-value \\
\hline Midwife talked about nutrition & $100(100 \%)$ & $78(94 \%)$ & $82(98.8 \%)$ \\
Midwife talked about warning signs & $100(100 \%)$ & $31(37.3 \%)$ & $0.01^{* *}$ \\
Instructed to rest to prevent problems & $62(62 \%)$ & $78(94 \%)$ & 0.27 \\
Instructed to sleep under a mosquito net & $91(91 \%)$ & $72(86.7 \%)$ & $60(72.3 \%)$ \\
Instructed to eat an extra meal daily & $97(97 \%)$ & $15(18.3 \%)$ & 0.45 \\
Instructed to drink plenty of fluids & $96(96 \%)$ & $75(90.4 \%)$ & $0.01^{* *}$ \\
Instructed to watch for problems \& report to clinic & $38(38 \%)$ & $96(96 \%)$ & $0.01^{* *}$ \\
Instructed to take iron tablets to prevent problems & & & 0.13 \\
\hline
\end{tabular}

${ }^{*} p \leq .05 ;{ }^{* *} p \leq .01$

$(<0.01)$ and a significantly greater number of women enrolled in group care intended to use postpartum family planning $(\mathrm{p}=<0.01)($ Table 6$)$.

\section{Medical record review}

A review of medical records was also conducted to examine health outcomes of the mother and newborn. The majority of births occurred at the hospital with no significant difference between groups of women giving birth at home. Women who reported delivering at home were interviewed and their antenatal cards reviewed at the time of their postnatal check. Only $4 \%$ of women enrolled in group ANC $(n=4)$ and $3.6 \%$ of women enrolled in individual care $(n=3)$ delivered at home $(p=0.89)$. One stillbirth occurred in each group. All women received adequate coverage of tetanus toxoid as well as intermittent preventive therapy for malaria during their pregnancy. There were no significant differences in Apgar scores at one and 5 minutes or in birth weight between groups (Table 7).

\section{Discussion}

Study results indicate the efficacy of group ANC to provide important information in a manner which improves women's ability to retain, understand, and utilize health messages.

Birth preparedness and complication readiness is a strategy widely used in low-resource countries to promote the timely use of skilled maternal and neonatal care, especially during childbirth. The cornerstones of birth preparedness and complication readiness include such behaviors as raising awareness of danger signs; improving problem recognition and reducing delay in deciding to seek care; choosing a birth location and provider in advance; knowing the location of the nearest skilled provider; obtaining basic safe birth supplies; and identifying someone to accompany them to the facility when labor begins [39]. Women in our study enrolled in group care reported significantly higher rates for discussing with the midwife where to deliver and arranging emergency transport in case of a problem as well as to have saved money for their birth.

Table 4 Birth Preparedness and Complication Readiness

\begin{tabular}{llll}
\hline Topic & Group $(n=100)$ & Individual $(n=83)$ & $p$-value \\
\hline Arranged emergency transport & $98(98 \%)$ & $69(83.1 \%)$ & $0.01^{* *}$ \\
Arranged money to prepare for delivery & $99(99 \%)$ & $67(80.7 \%)$ & $<.01^{* *}$ \\
ANC care influenced place of delivery & $62(62 \%)$ & $28(33.7 \%)$ & $0.01^{* *}$ \\
Talked with midwife about where to deliver & $51(51.5 \%)$ & $20(24.7 \%)$ & $76(91.6 \%)$ \\
Arranged layette for baby & $92(92 \%)$ & $79(95.2 \%)$ & $0.01^{* *}$ \\
Obtained supplies for delivery & $95(95 \%)$ & & 0.92 \\
Knew Danger Signs & & $81(97.6 \%)$ & 0.96 \\
Vaginal bleeding & $99(99 \%)$ & $15(18.1 \%)$ & 0.46 \\
Fever & $24(24.0 \%)$ & $24(28.9 \%)$ & 0.33 \\
Pain in breast or abdomen & $46(46 \%)$ & $61(73.5 \%)$ & $0.02^{*}$ \\
Swollen face or hands & $72(72 \%)$ & $64(77.1 \%)$ & 0.82 \\
Headache/blurred vision & $91(91 \%)$ & $14(16.9 \%)$ & 0.98 \\
Reduced or no fetal movement & $17(17 \%)$ &
\end{tabular}

${ }^{*} p \leq .05 ;{ }^{* *} p \leq .01$ 
Table 5 Breastfeeding Knowledge

\begin{tabular}{llll}
\hline Topic & Group $(n=100)$ & Individual $(n=83)$ & $p$-value \\
\hline Start to breastfeed as soon as possible after delivery & $90(90 \%)$ & $55(66.3 \%)$ & $<0.01^{* *}$ \\
Breastfeed every 2-4 h during day & $79(79 \%)$ & $53(63.9 \%)$ & $1(1.2 \%)$ \\
Breastfeed at least once a night & $16(16 \%)$ & $63(75.9 \%)$ & $<.02^{*}$ \\
Breastfeed until baby is at least 6 months old & $90(90 \%)$ & $75(90.4 \%)$ & $<0.01^{* *}$ \\
Do not give water to your baby & $94(94 \%)$ & $72(86.7 \%)$ & 0.36 \\
Do not give supplemental feedings & $84(84 \%)$ & 0.61
\end{tabular}

${ }^{*} p \leq .05 ;{ }^{* *} p \leq .01$

Exclusive breastfeeding up to 6 months of age is recommended by WHO for all newborns [40]. Women enrolled in the group ANC model of care were able to state significantly more positive practices associated with exclusive breastfeeding than women in individual care.

Only a minority of women (23.5\%)enrolled in individual care reported discussing newborn problems with the midwife during ANC visits. Yet the majority of maternal and newborn deaths in the world occur in the first month after birth with half of all maternal deaths occurring in the first $24 \mathrm{~h}$ [41] and $66 \%$ in the first week following birth [42].

Additionally, our findings reflect the high level of care already being delivered at this facility. Both groups exhibited high literacy related to not giving supplemental feedings or water to their newborn. There was also no significant difference between women enrolled in group or individual ANC who reported they were instructed to sleep under mosquito netting and take iron tables to prevent anemia. Overall, women in both groups were able to identify the majority of danger signs to watch for during pregnancy.

While the number of miscarriages (6 women in individual ANC vs. 4 women in group ANC) and transfer of care to another facility (7 women in each group) is similar between groups, $20 \%$ of women in individual ANC $(n=24)$ vs. $7 \%$ of women in the group ANC $(n=9)$ failed to return for care after their first or second appointment with the midwife. Unfortunately, we were not able to follow up with these women to understand the reasons for this higher dropout rate from women enrolled in individual care.

\section{Limitations}

There are several limitations to this research. The women recruited for this study represented a convenience sample from one district hospital in one urban region of Ghana, minimizing the ability to generalize our findings. The same midwives provided care to women in group ANC and individual ANC in this study; therefore, it is possible some of the techniques learned during the training of trainers related to communication and information sharing were adopted and used by the midwives during individual antenatal care. The research assistant was not blinded to the type of ANC women were receiving potentially biasing her during data collection.

Despite these limitations, our findings provide evidence of the potential impact of providing ANC to women using a group care model in a low-resource global setting. Our findings support the hypothesis that group ANC can effectively improve women's comprehension of educational messages received during pregnancy.

While there is a body of evidence developing on how group care impacts patient satisfaction and improves communication between providers and pregnant women $[14,16,25]$, exploration into what components of group care make it more effective in changing health behaviors is lacking in the literature. Future research is needed to understand why women drop out of care and whether group ANC is more effective at keeping women engaged in maternal health services long term. Future experimental design research is needed to examine the impact of group ANC on maternal and newborn outcomes and should expand into both peri-urban and rural areas to examine the effectiveness of group ANC on diverse populations.

Table 6 Newborn and Postpartum Self-care Knowledge

\begin{tabular}{llll}
\hline Topic & Group $(n=100)$ & Individual $(n=83)$ & $p$-value \\
\hline Knows excessive bleeding postpartum is a danger sign & $94(94 \%)$ & $60(72 \%)$ & $3(3.6 \%)$ \\
Knows fever postpartum is a danger sign & $10(10 \%)$ & $19(23.5 \%)$ & $0.091^{* *}$ \\
Midwife discussed newborn problems during antenatal care & $81(82.7 \%)$ & $58(63.0 \%)$ & $24(31.6 \%)$
\end{tabular}

${ }^{*} p \leq .05 ;{ }^{* *} p \leq .01$ 
Table 7 Maternal \& Newborn Outcomes

\begin{tabular}{|c|c|c|c|}
\hline Newborn Outcomes & $\begin{array}{l}\text { Group } \\
(n=100)\end{array}$ & $\begin{array}{l}\text { Individual } \\
(n=83)\end{array}$ & $p$-value \\
\hline $\begin{array}{l}\text { Apgar at } 1 \text { min } \\
\text { Mean (SD) }\end{array}$ & $7.7(1.5)$ & $7.6(1.2)$ & 0.65 \\
\hline $\begin{array}{l}\text { Apgar at } 5 \text { min } \\
\text { Mean (SD) }\end{array}$ & $9.2(1.8)$ & $9.0(1.2)$ & 0.52 \\
\hline $\begin{array}{l}\text { Birth weight in grams } \\
\text { Mean (SD) }\end{array}$ & $3103(491.1)$ & $3073(487.9)$ & 0.68 \\
\hline $\begin{array}{l}\text { Low birth weight } \\
(<2500 \mathrm{~g})\end{array}$ & $6(6 \%)$ & $6(7.2 \%)$ & 0.74 \\
\hline Respiratory distress & $4(4 \%)$ & $4(4.9 \%)$ & 0.8 \\
\hline Sepsis & $1(1 \%)$ & $1(1.3 \%)$ & 0.86 \\
\hline \multicolumn{4}{|l|}{ Maternal Outcomes } \\
\hline $\begin{array}{l}\text { Number of ANC visits } \\
\text { Mean (SD) }\end{array}$ & $7.4(1.3)$ & $6.4(2.0)$ & $<0.01^{* *}$ \\
\hline Caesarean section & $17(17 \%)$ & $12(14.5 \%)$ & 0.64 \\
\hline $\begin{array}{l}\text { Hgb immediately before delivery } \\
\text { Mean (SD) }\end{array}$ & $11.5(1.2)$ & $11.6(1.1)$ & 0.91 \\
\hline Pre-eclampsia & $2(2 \%)$ & $1(1.2 \%)$ & 0.67 \\
\hline Postpartum hemorrhage & $1(1 \%)$ & $2(2.4 \%)$ & 0.46 \\
\hline
\end{tabular}

\section{Conclusion}

Group ANC offers a high impact alternative to standard ANC with the potential to improve quality, generate demand for services, increase healthy behaviors and promote respectful care in low-resource settings.

Patient-provider interactions during ANC provide the opportunity to identify and treat numerous problems as well as a setting to improve women's health literacy on how to prevent and recognize problems in themselves, prepare for birth, and care for their soon-to-be-born baby. Findings from our study add to a growing body of literature on the use of group ANC to improve maternal and newborn care.

\section{Additional files}

Additional file 1: Chart Review Guide. (PDF 148 kb)

Additional file 2: Demographic Data. (PDF $88 \mathrm{~kb}$ )

Additional file 3: Summative Evaluation for women. (PDF $263 \mathrm{~kb}$ )

\section{Abbreviations}

ANC: antenatal care; BEmONC: Basic emergency obstetric care; USAID: United States agency for international development; WHO: World Health Organization

\section{Acknowledgements}

Not applicable.

\section{Funding}

The development of this article was supported in part by research grant 1 K01 TW008763-01A1 from Fogarty International, National Institutes of Health (Dr. Jody R. Lori, PI). The content is solely the responsibility of the authors and does not necessarily represent the official views of Fogarty International or the National Institutes of Health.

\section{Availability of data and materials}

The datasets used and/or analysed during the current study available from the corresponding author on reasonable request.

\section{Authors' contributions}

$J L, C B$ and RA conceived of the study, participated in its design and coordination, carried out data collection, performed statistical analysis, and was involved in drafting and revising the manuscript. TB contributed to data analysis and interpretation of data and was involved in drafting and revising the manuscript. $\mathrm{HO}$ participated in the study design and coordination, carried out data collection, and was involved in drafting and revising the manuscript. All authors read and approved the final manuscript.

\section{Ethics approval and consent to participate}

Institutional review board approval for the study was obtained from the University of Ghana Noguchi Memorial Institute for Medical Research (research study \#023/11-12); the Kwame Nkrumah University of Science and Technology Committee on Human Research, Publications and Ethics (CHRPE/ AP/091/12); and the University of Michigan's Institutional Review Board (HUM00054141). A written informed consent was used. If women were unable to read, the research assistant read the document to them. All women provided written consent through a signature or mark entered onto the informed consent document.

\section{Consent for publication}

Not applicable.

\section{Competing interests}

The authors declare that they have no competing interests.

\section{Publisher's Note}

Springer Nature remains neutral with regard to jurisdictional claims in published maps and institutional affiliations.

\section{Author details}

${ }^{1}$ Department of Health Behavior and Biological Sciences, University of Michigan, School of Nursing, 400 N. Ingalls Bldg, Ann Arbor, Ml 48109, USA. ${ }^{2}$ Ghana Health Service, Manhyia District Hospital, Kumasi, Ghana. Institute for Health Care Policy \& Innovation, University of Michigan, NCAC Bldg 16, SPC 2800, Ann Arbor, MI 48109, USA. ${ }^{4}$ School of Public Health, University of Ghana, POBox GP4236, Accra, Ghana.

Received: 28 October 2016 Accepted: 5 July 2017

Published online: 14 July 2017

\section{References}

1. United Nations. Millennium Development Goals Report. 2015. http://www un.org/millenniumgoals/2015_MDG_Report/pdf/ MDG\%202015\%20rev\%20(July\%201).pdf. Accessed 4 April 2017.

2. WHO, UNICEF. Every newborn action plan. 2014. http://apps.who.int/iris/ bitstream/10665/127938/1/9789241507448_eng.pdf?ua=1 Accessed 4 Apr 2017.

3. WHO, UNICEF, UNFPA, World Bank Group \& the United Nations Population Division. Trends in Maternal Mortality: 1990-2015. 2016. http://apps.who.int/ iris/bitstream/10665/194254/1/9789241565141_eng.pdf?ua=1 http://www. who.int/reproductivehealth/publications/monitoring/maternal-mortality2015/en/. Accessed 4 Apr 2017

4. WHO, WHO recommendations on antenatal Care for a Positive Pregnancy Experience. 2016. http://www.who.int/reproductivehealth/publications/ maternal_perinatal_health/anc-positive-pregnancy-experience/en/ Accessed 6 Apr 2017.

5. Batterham RW, Hawkins M, Collins PA, Buchbinder R, Osborne RH. Health literacy: applying current concepts to improve health services and reduce health inequalities. Public Health. 2016;132:3-12.11.

6. Renkert S, Nutbeam D. Opportunities to improve maternal health literacy through antenatal education: an exploratory study. Health Promot Int. 2001;16(4):381.

7. Sorensen K, Van den Broucke S, Fullam J, et al. Health literacy and public health: a systematic review and integration of definitions and models. BMC Public Health. 2012;12(1):80. doi:10.1186/1471-2458-12-80. 
8. von Wagner C, Steptoe A, Wolf MS, Wardle J. Health literacy and health actions: a review and a framework from health psychology. Health Educ Behav. 2009;36(5):860-77. doi:10.1177/1090198108322819.

9. Hodgins S, Tielsch J, Rankin K, Robinson A, Kearns A, Caglia J. A new look at care in pregnancy: simple, effective interventions for neglected populations. PLoS One. 2016;11(8):e0160562. doi:10.1371/journal.pone.0160562.

10. Villar J, Ba'aqeel H, Piaggio G, Lumiganon P, Belizan JM, Farnot U, et al. WHO antenatal care randomized trial for the evaluation of a new model of routine antenatal care. Lancet. 2001;357(9268):1551-64.

11. Hofmeyr GJ, Hodnett E. Antenatal care packages with reduced visits and perinatal mortality: a secondary analysis of the WHO antenatal care trialcommentary: routine antenatal visits for healthy pregnant women do make a difference. Reprod Health. 2013;10:20.

12. Mathai M. To ensure maternal mortality is reduced, quality of care needs to be monitored and improved alongside increasing skilled delivery coverage rates. BJOG. 2011;118(Suppl. 2):12-4.

13. Hodgins S, D'Agostino A. The quality-coverage gap in antenatal care: toward better measurement of effective coverage. Glob Health Sci Pract Adv. 2014; doi: 10.9745/GHSP-P-13-001 76

14. Lori JR, Munro ML, Chuey MR. Use of a facilitated discussion model for antenatal care to improve communication. Int J Nurs Stud. 2015;(15): 00098X. doi: 10.1016/j.ijnurstu.2015.03.018. PubMed PMID: 25862409; PubMed Central PMCID: PMC4592694

15. Eisenstat S, Siegel A, Carlson K, Ulman K. Putting Group Visits into practice: a practical overview to preparation, implementation, and maintenance of group visits at Massachusetts General Hospital. http://www.massgeneral.org/ stoecklecenter/assets/pdf/group_visit_guide.pdf. 2012. Accessed 13 July 2016.

16. Ruiz-Mirazo E, Lopez-Yarto M, McDonald SD. Group prenatal care versus individual pernatal care: a systematic review and meta-analyses. J Obstet Gynaecol Can. 2012;34(3):223-9.

17. Anya SE, Hydara A, Jaiteh JE. Antenatal care in the Gambia: missed opportunity for information, education and communication. BMC Pregnancy Childbirth. 2008;8:9.

18. Pembe AB, Carlstedt A, Urassa, et al. Quality of antenatal care in rural Tanzania: counselling on pregnancy danger signs. BMC Pregnancy Childbirth. 2010;10:35.

19. Duysburgh E, Ye M, Williams A, Massawe S, et al. Counseling on and women's awareness of pregnancy danger signs in selected rural health facilities in Burkina Faso, Ghana and Tanzania. Trop Med Int Health. 2013;18(12):1498-509.

20. Kaso, M. \& Addisse, M. Birth preparedness and complication readiness in robe Woreda, Arsi zone, Oromia region, Central Ethiopia: a cross-sectional study. 2014

21. Lori JR, Dahlem CH, Ackah JV, Adanu RM. Examining antenatal health literacy in Ghana. J Nurs Scholarsh. 2014;46(6):432-40. doi:10.1111/jnu.12094. PubMed PMID: 24930782; PubMed Central PMCID: PMC4471845

22. WHO. Counselling for maternal and newborn health care: a handbook for building skills. 2013. http://www.who.int/maternal_child_adolescent/ documents/9789241547628/en/. Accessed 30 Sept 2016.

23. Group Health Cooperative. Group visit starter kit: improving chronic illness care. 2001. https://www.aace.com/files/groupvisitstarterkit.pdf. Accessed 4 Apr 2017.

24. Ickovics J, Kershaw T, Westdahl C, et al. Group prenatal care and perinatal outcomes: a randomized trial. Obstet Gynecol. 2007;110:330-9.

25. Jafari F, Eftekhar H, Fotouhi A, Mohammad K, Hantoushzadeh S. Comparison of maternal and neonatal outcomes of group versus individual prenatal care: a new experience in Iran. Health Care Women Int. 2012;31:571-84.

26. Kennedy $H$, Farrell $T$, Paden $R$, et al. A randomized clinical trial of group prenatal care in two military settings. Mil Med. 2011;176:1169-77.

27. Klima C, Norr K, Vonderhold S. Introduction of CenteringPregnancy in a public health clinic. J Midwifery Womens Health. 2009;54:27-34.

28. Patil C, Abrams E, Klima C, et al. CenteringPregnancy-Africa: a pilot of group antenatal care to address millennium development goals. Midwifery. 2013;29:1190-8.

29. Buffington ST, Sibley LM, Beck DR, Armbruster DA. Home Based Life Saving Skills. 2nd edition. Silver Spring: American College of Nurse Midwives; 2010.

30. WHO. Standards for maternal and neonatal care. Birth and emergency preparedness in antenatal care. 2006 [cited 30 Dec 2013]; http://www.who. int/reproductivehealth/publications/maternal_perinatal_health/emergency preparedness_antenatal_care.pdf. Accessed 27 September 2016.

31. WHO. WHO recommendations on health promotion interventions for maternal and newborn health. 2015. http://www.who.int/maternal_child_ adolescent/documents/health-promotion-interventions/en/. Accessed 23 Sept 2016.

32. Carroli G, Piaggio G, Khan-Neelofur D. WHO systematic review of randomised controlled trials of routine antenatal care. Lancet. 2001; 357(9268):1565-70.

33. WHO. Nutrition: exclusive breastfeeding. 2016. http://www.who.int/nutrition/ topics/exclusive_breastfeeding/en/. Accessed 25Apr 2016.

34. USAID. Healthy timing and spacing of pregnancy 101: everything you want to know about healthy timing and spacing of pregnancy. 2006. http://www who.int/pmnch/topics/maternal/htsp101.pdf. Accessed 19 Mar 2016.

35. Ross JA, Winfrey WL. Contraceptive use, intention to use and unmet need during the extended postpartum period. Int Fam Plan Perspect. 2001 27(1):20-7.

36. Ghana Statistical Service (GSS), Ghana Health Service (GHS), and ICF International. Ghana Demographic and Health Survey 2014. Rockville, Maryland, USA: GSS, GHS, and ICF International. United Nations 2015. Millennium Development Goals Report. https://dhsprogram.com/pubs/pdf/ FR307/FR307.pdf. Accessed 13 July 2016.

37. Cohen J. A power primer. Psychol Bull. 1992;112:155-9

38. Elashoff JD. nQuery advisor version 7.0 User's guide. Cork, Ireland: Statistical Solutions Ltd.; 2007.

39. JHPIEGO. Maternal and neonatal health program: monitoring birth preparedness and complication readiness; tools and indicators for maternal and newborn health, Hopkins: Bloomberg School of Public Health, Center for Communication Programs, family care international. 2004. http://pdf. usaid.gov/pdf docs/Pnada619.pdf. Accessed 25 Apr 2016.

40. WHO. Health topics: breastfeeding. 2016. http://www.who.int/topics/ breastfeeding/en/. Accessed 19 Mar 2016.

41. Lawn JE, Kinney $M$, Blencowe $H$. Every newborn, an executive summary for the lancet series. Lancet. 2014;384(9938):1-8.

42. Nour N. An introduction to maternal mortality reviews. Obstet Gynaecol. 2008;1:77-81.

\section{Submit your next manuscript to BioMed Central and we will help you at every step:}

- We accept pre-submission inquiries

- Our selector tool helps you to find the most relevant journal

- We provide round the clock customer support

- Convenient online submission

- Thorough peer review

- Inclusion in PubMed and all major indexing services

- Maximum visibility for your research

Submit your manuscript at www.biomedcentral.com/submit

) BioMed Central 